\title{
The association between core job components, physical activity, and mental health in African academics in a post-COVID-19 context
}

\author{
Nestor Asiamah ${ }^{1,2}$ (1) $\cdot$ Faith Muhonja ${ }^{3} \cdot$ Akinlolu Omisore $^{4}$. Frank Frimpong Opuni ${ }^{5} \cdot$ Henry Kofi Mensah $^{6}$. \\ Emelia Danquah $^{7}$. Simon Mawulorm Agyemang ${ }^{8} \cdot$ Irene Agyemang $^{9} \cdot$ Sylvester Hatsu $^{10} \cdot$ Rita Sarkodie Baffoe $^{11}$. \\ Eric Eku ${ }^{12} \cdot$ Christiana Afriyie Manu ${ }^{11}$
}

Accepted: 22 June 2021 / Published online: 8 July 2021

(C) The Author(s), under exclusive licence to Springer Science+Business Media, LLC, part of Springer Nature 2021

\begin{abstract}
This study examined the association between core job components (i.e. teaching, research, and student assessment), physical activity (PA), and mental health in a post-COVID-19 context. An online questionnaire administered via Google Forms was used to gather data from 1064 African academics in four countries. A sensitivity analysis was applied to adjust for covariates. Data were analyzed with the hierarchical linear regression analysis. The average age of participants was 44 years. The study found that PA was positively associated with research but negatively associated with student assessment. Mental health was positively associated with onsite teaching but negatively associated with online teaching and research. PA did not predict mental health and mediate the relationship between the job components and mental health. It is concluded that PA may not increase mental health in African academics in a post-COVID-19 situation that required the resumption of work while observing social distancing protocols.
\end{abstract}

Keywords Teaching $\cdot$ Research $\cdot$ Physical activity $\cdot$ Mental health $\cdot$ Academics $\cdot$ Africa; assessment; neighborhood walkability

\section{Introduction}

A wealth of research suggests that the maintenance of physical activity (PA) over the life course protects against morbidity and mortality (Asiamah et al., 2020; Thornton et al., 2016; Guthold et al., 2018). Empirical studies have also evidenced that PA reduces the risk of non-infectious diseases, namely cardiovascular disorders (i.e. stroke, hypertension, diabetes),

Nestor Asiamah

nestor.asiamah@myport.ac.uk;

nestorkwabena.asiamah@gmail.com; nestor.asiamah@ace-gh.org

Faith Muhonja

muhonjaf@gmail.com; http://orcid.org/0000-0002-2451-4669

Akinlolu Omisore

akinlolu.omisore@uniosun.edu.ng; http://orcid.org/0000-0002-

3393-5721

Frank Frimpong Opuni

fofrimpong@atu.edu.gh; http://orcid.org/0000-0001-8794-6541

Henry Kofi Mensah

hkmensah@knust.edu.gh; http://orcid.org/0000-0001-7580-8125

Emelia Danquah

addom123@yahoo.com neurodegenerative disorders (e.g. Alzheimer's disease), and cancers (Christie et al., 2020; Dunton et al., 2020; Thivel et al., 2018; Thornton et al., 2016). In contrast, the foregoing risks are increased by physical inactivity (PI) (Thivel et al., 2018; Thornton et al., 2016), defined as non-achievement of recommended PA levels (Thornton et al., 2016). A standard recommendation from the World Health Organization for the general population is at least 60 min per week of vigorous PA,

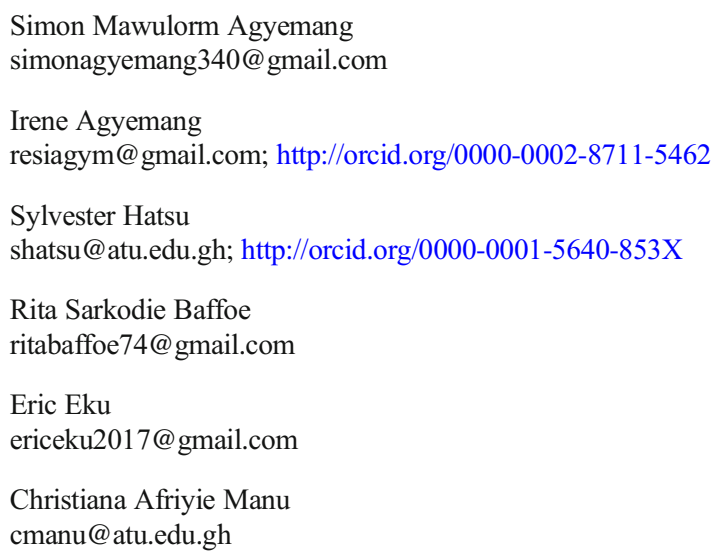

Extended author information available on the last page of the article 
or 150 min per week of moderate PA (Ding et al., 2020). With this guideline, it is understandable that PA represents a hallmark for healthy living. No doubt, public health interventions aimed at increasing PA in all segments of the population are apex health promotion strategies. Several programs have been rolled out on a global scale by stakeholders (e.g. governments, the World Health Organization (WHO)) to increase PA. Neighborhood design to encourage PA (Chudyk et al., 2017; Christman et al., 2019) and clinical exercise counseling (Thivel et al., 2018; Thornton et al., 2016) are examples of such programs and represent the flagship of contemporary public health interventions. It is, however, disheartening that the level of PA insufficiency in the general population, currently estimated at $28 \%$, is still high and connotes that the WHO's goal of reducing PI by $10 \%$ by 2030 may not be achieved (Guthold et al., 2018).

The aforesaid empirical evidence suggests that interventions aimed at reducing PI would increase PA and confer health benefits on individuals. However, several conditions (i.e. frailty, disability, and occupational sitting) can make it difficult for individuals to maintain PA (Lindsay et al., 2016; D'Avanzo et al., 2017), which means that PA interventions may not benefit people with these conditions. More specifically, occupational sitting is a major public health concern (Chau et al., 2012; Picavet et al., 2016; Proper et al., 2007; Proper et al., 2012) because it is an entrenched behavior that discourages PA, increases health risks, and makes it less possible for employees to meet recommended PA levels (Greer, 2015). Suffice it to say that full-time employees in administrative roles spend most of their waking time sitting and, in effect, fail to utilize walkable neighborhood factors (e.g. parks, gardens, social networks) that are provided through PA promotion programs and other public health interventions. For this reason, occupational sitting and PI in employees can be expected to increase significantly in the coming years as industrialization intensifies and new technologies (e.g. computers, artificial intelligence, and robotics) call for the replacement of factory hands with machines.

Worse yet, the outbreak of the Coronavirus 2019 disease (COVID-19) has increased the foregoing risks and made the future of global health gloomier. A plethora of studies recently reported increased PI and sedentary behavior as consequences of COVID-19 social distancing measures (Asiamah et al., 2020; Armitage \& Nellums, 2020; Dunton et al., 2020). Noteworthy are studies reporting a negative association between individual-level social distancing efforts, PA, and mental health (Asiamah et al., 2020; Venkatesh \& Edirappuli, 2020; Dunton et al., 2020). Deductively, the general population faces a higher risk of PI and decline in mental health owing to COVID-19. Currently, academics in many African countries may be among employees facing the highest declines in mental health attributable to COVID-19 social distancing measures. This assertion is premised around some of our observations as academics. Many African universities and colleges re-opened by August 31, 2020 (Muhumuza \& Odula, 2020; Upoalkpajor \& Upoalkpajor, 2020), which made it necessary for academics to return to work. Even so, some academics had to switch to online teaching or comply with more stringent social distancing measures on campus (Muhumuza \& Odula, 2020; Upoalkpajor \& Upoalkpajor, 2020; Dhawan, 2020). Research has shown that the use of computers (for teaching online) is a leading cause of PI (George et al., 2014; Greer, 2015). If social distancing measures before the end of August 2020 were associated with mental health struggles as evidenced by Asiamah and colleagues (2020), then the above-mentioned steps accompanied by the reopening of universities should more significantly reduce mental health in academics. Needless to say, academics would be overwhelmed by working remotely or with less PA while coping with COVID-19-related changes in work pattern, economic fallout, and anxiety.

What is uncertain is how the key job components of academics, which are teaching (i.e. onsite teaching and online teaching), research, and student assessment (Greer, 2015; Torp et al., 2017), would affect mental health in a time when individuals are expected to simultaneously observe social distancing measures and use resources quite new to them (e.g. online classrooms) to perform job tasks. Studies conducted recently suggest that mental health decline is associated with social distancing measures (Venkatesh \& Edirappuli, 2020; Asiamah et al., 2020). More so, the core job tasks of academics are largely sedentary (Greer, 2015; Hogan et al., 2016; Torp et al., 2017) and can, therefore, be associated with mental health struggles. Interestingly, PA can counter the negative influences of the job components on mental health or ameliorate sedentariness and its negative effect on mental health in a situation where academics concurrently perform job tasks and observe social distancing measures (Venkatesh \& Edirappuli, 2020; Asiamah et al., 2020). We, nevertheless, argue based on the combined imports of the Job DemandsResources (JD-R) Theory and Health Belief Model (HBM) as well as recent commentaries (Venkatesh \& Edirappuli, 2020; Asiamah et al., 2020) that PA in a post-COVID-19 context would not be sufficient to support mental health and is, therefore, unlikely to mediate the relationship between the core job components and mental health. This reasoning signifies the importance of interventions aimed at increasing PA in academics and related populations in a post-COVID-19 context. We operationally define a post-COVID-19 period or context as the time just after the reopening of schools when faculties in some African countries (Ghana, Nigeria, Kenya, etc.) were asked to resume work and perform traditional job tasks while observing recommended social distancing protocols. In the post-COVID-19 context, African academics were required to engage in online teaching for the first time, increase online teaching time, or teach in a physical classroom or on-site with 
minimal social engagement with students and colleagues (Jacob, 2020; Varea \& González-Calvo, 2020). These changes would make life in the post-COVID-19 period quite different and difficult for academics.

Given the imports of the foregoing theories (which are later discussed in this paper) and the fact that academics had to engage in both sedentary job tasks (i.e., online teaching) and PA-supported work (e.g. on-site teaching), it is uncertain if the relationship between the job components and mental health can be mediated by PA. A study that investigates the relationship between the core job components and mental health as well as this mediating role can complement the evidence needed for relevant PA interventions. The aim of this study was, therefore, to assess the relationship between the core job components, PA, and mental health in a post-COVID-19 context. The said mediation role of PA was also evaluated. Though industry engagement and administrative work are other aspects of academic work, we focused on only core academic job tasks (i.e., on-site teaching, online teaching, research, and student assessment) that were sufficiently performed and could be measured in the post-COVID-19 context. This study is necessary because COVID-19 may take a longer time to eradicate. In the event that COVID-19 is eradicated or contained, a related or more contagious infectious disease may breakout in the future (Asiamah et al., 2020). As such, the post-COVID-19 situation described above may be with humanity for a long time or repeat itself in the future. This study is also a response to recent calls (Jacob, 2020; Upoalkpajor \& Upoalkpajor, 2020) for research on the effect of COVID-19 on teachers and students and is the exploratory phase of a potential randomized controlled trial.

\section{Theoretical Framework}

The relationship between academics' job components, PA, and mental health in a post-COVID-19 context can be explained with the JD-R formulated by Demerouti et al. (2001) and the HBM developed by Hochbaum et al. (1952). The JD$\mathrm{R}$ is a theory that recognizes occupational stress as the consequence of the imbalance between job demands and the employee's resources. Examples of job demands are personal and organizational aspects of a job that require sustained physical or psychosocial efforts (e.g., being resilient). In a postCOVID-19 context, personal aspects recently reported by researchers (Asiamah et al., 2020) include national and institutional social distancing protocols and their economic consequences such as reduced savings and income. These individual outcomes are the direct repercussions of the organizational aspects, including strict enforcement of social distancing protocols and delayed payment of salaries due to financial difficulties faced by universities during the pandemic (Ahlburg, 2020; Blackmore, 2020; Muhumuza \& Odula, 2020).
Resources, on the other hand, are organizational and personal factors (e.g., supervisor support, autonomy, self-efficacy, functional capacity, physical health) that stimulate personal growth and learning. For instance, support from an employee's supervisor can buffer burnout and stress associated with job demands. The HBM, on the other hand, assumes that people's beliefs about health problems, perceived benefits of action, barriers to action, and self-efficacy explain engagement in health-supporting behaviors such as PA. Moreover, a health-supporting behavior requires a stimulus or cue to action (e.g., feelings of depression and anxiety). According to this model, academics are more likely to participate in PA in the post-COVID-19 period if they know and value the health benefits of PA, especially in a social distancing context, understand how to navigate the barriers to PA, and evaluate their susceptibility to PI and its health risks. Any prevailing health conditions and developing psychological stress are stimuli that would speed up participation in PA. Even so, the above drivers of PA or health behavior are subject to the individual's self-efficacy; people with low or no selfefficacy are unlikely to participate in a pro-health behavior even if they know about the health benefits of this behavior and barriers to it (Clark et al., 2020). Recent debate recognizes self-efficacy as an important antecedent to health-promoting behavior (Clark et al., 2020; Shahnazi et al., 2020).

In a post-COVID-19 context, PA would be explained by factors characterized by the JD-R theory and HBM. Some of the factors linked to the JD-R theory are job demands (i.e., teaching, assessing students, and researching while observing social distancing), which would impel academics to engage in PA or sedentary behavior associated with work. Some researchers (Barello et al., 2021; Meyer et al., 2021) have reasoned based on the JD-R theory that job demands would be more than resources in social distancing contexts. That is, an imbalance between demands and resources (i.e., demands being stronger than resources) is more probable in a social distancing setting because stress and related health risks can outplay the limited resources such as social support and selfefficacy available. To add, academics with limited resources would feel obligated to perform job tasks in response to adapted practices from their universities for some reasons. First, thousands of job losses due to COVID-19 were reported during the pandemic (Blackmore, 2020; Barello et al., 2021); hence, rational academics would want to stick to their jobs and satisfy their employees even if they have limited resources and face psychological problems. Secondly, academics may engage in job tasks in the post-COVID-19 era to avoid boredom or psychological problems from COVID-19 that qualify as cues to PA. If so, academic work engagements would affect PA in a post-COVID-19 context. For example, on-site teaching roles involve walking (at least in the classroom) and other physical activities. In contrast, a reduction in PA can be the consequence of a job task requiring sitting and other sedentary 
behaviors. Job demands that come in the form of sedentary job tasks (i.e., online teaching) would, therefore, curtail PA. Thus, PA would increase with job tasks (e.g., on-site teaching) that involve walking and other physical activities but decrease as other job tasks that involve sitting and other sedentary behaviors increase. In this vein, the health benefits of PA are likely to be canceled or outplayed by sedentary behavior or PI.

The HBM also implies that the individual would engage in PA depending partly on his self-efficacy and knowledge about the health benefits of PA, hereby referred to as 'PA knowledge'. Thus, PA knowledge, especially in a social distancing context, can encourage engagement in PA. This being so, academics' self-efficacy and PA knowledge can encourage them to exercise indoors or participate in PA in the neighborhood in isolation. Deductively, even those who spend many hours teaching online are likely to participate in PA. In a recent study conducted in Ghana, about $64 \%$ of the sample participated in PA during a lockdown (Asiamah et al., 2020). Other studies (Shahnazi et al., 2020; Clark et al., 2020) also reveal that participation in PA during the pandemic was due to widespread PA knowledge. This being so, voluntary PA performed off the job can buffer sedentary behavior from online teaching and add to PA from tasks such as on-site teaching. This is to say that PA among academics in the post-COVID19 context may be performed off the job based on voluntary engagement in physical activities due to one's PA knowledge. Based on the HBM, therefore, PA can be positively associated with all the job tasks, including online teaching, in a postCOVID-19 context.

Further to the above, the JD-R theory implies that selfefficacy and PA knowledge are personal resources that can contribute to a balance between job demands and resources. Similarly, the potential imbalance between job demands and resources can be reduced or mitigated by self-efficacy and PA knowledge. Physical function, age (i.e., being young), income, and other personal factors can also serve as resources contributing to a balance between demands and resources. The JD-R and HBM overlap in a context where self-efficacy and PA knowledge serve as personal resources utilized to maintain PA despite individuals' involvement in sedentary tasks and observance of social distancing protocols. This reasoning is based on the HBM's assumption that any of the job components can be associated with PA if academics harness their self-efficacy and PA knowledge to avoid PI. In a nutshell, the HBM implies that all job components can be positively associated with PA in a post-COVID-19 context where resources (i.e., physical health, functional status, PA knowledge, self-efficacy) are relished. Per the JD-R theory, these and other resources must balance or outplay job demands for one to engage in sufficient PA while working in a postCOVID-19 context. Putting the imports of the two theories together, it is understandable that resources would be limited in a post-COVID-19 setting, so job demands compounded by their psychosocial challenges (e.g., stress, anxiety) can disable self-efficacy and render PA knowledge unbeneficial. From this viewpoint, all the job components can be negatively associated with PA, though on-site teaching may involve more PA. If resources including PA knowledge and self-efficacy outweigh job demands, then academics would be able to overcome stress, anxiety, and other psychological problems, and voluntarily exercise in a post-COVID-19 context. From this standpoint, all the job components can be positively associated with PA, depending on how much voluntary PA is performed off the job. Thus, PA can be associated with the job components as depicted in Fig. 1, but whether these relationships are positive or negative cannot be predicted in a postCOVID-19 context. For this reason, it was necessary for the conceptual model represented by Fig. 1 to show two-tailed or non-directional hypotheses (i.e., H1-H4) regarding the associations between core job components and PA in a postCOVID-19 context.

Recent research (Ahlburg, 2020; Blackmore, 2020) suggests that the COVID-19 pandemic has caused dramatic changes to jobs worldwide. In universities, these changes include the adoption of online teaching, an increase in online teaching hours, or teaching on-site while observing social distancing measures (Asiamah et al., 2020; Nyenhuis e al., 2020). Drawing on the JD-R theory, these changes and their socioeconomic consequences (e.g., worry about job security, dwindling income, and not physically meeting social network members) are tied to job factors (e.g., job demands) and stimulate psychological stress, a risk factor for mental health declines. According to the HBM, factors such as psychological stress are stimuli or cues but can reduce self-efficacy and the ability of a person to engage in health-supporting behaviors, regardless of whether the individual knows about the benefits of these behaviors. In a post-COVID-19 context, personal and organizational resources recognized by the JD-R theory may be inadequate or unable to support PA because access to them is limited by social distancing. From another point of view, those who voluntarily engage in PA to avoid the risk of PI and health problems are not necessarily free from stress and mental health struggles; these people may already be experiencing psychological stress and related mental health issues linked to COVID-19 and its struggles. This being so, even PAsupported job tasks such as on-site teaching can be negatively associated with mental health in a post-COVID-19 context.

Research has shown that PA is positively associated with health outcomes, specifically mental health (Asiamah et al., 2020; Peluso \& de Andrade 2005; Veroma et al., 2017). Studies (Asiamah et al., 2020; Duncan et al., 2020; Meyer et al., 2020) conducted in response to COVID-19 have also shown that PA is positively associated with mental health in the general population. These pieces of evidence and the HBM suggest that PA among academics is positively associated with mental health. Nonetheless, this relationship may be 


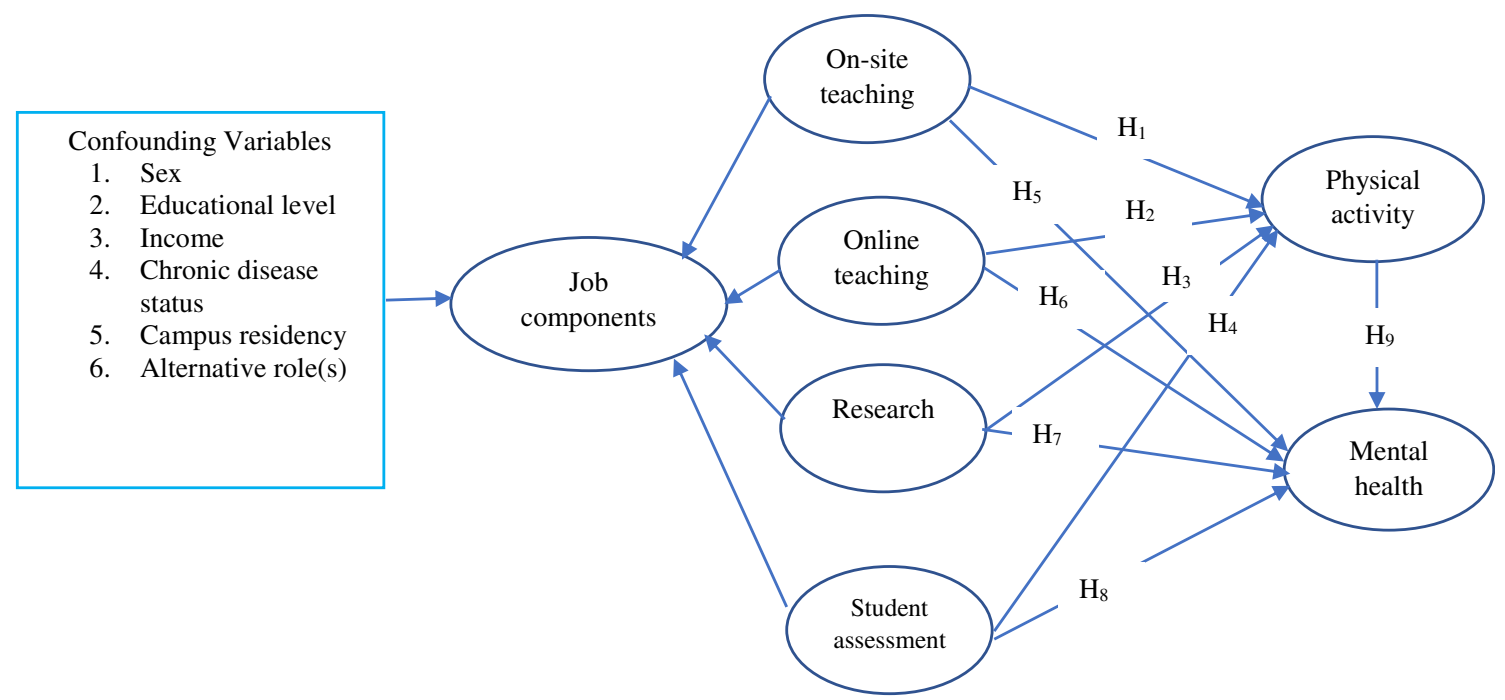

Fig. 1 The association between core job components, PA, and mental health in a post-COVID-19 context. Note: The arrow between confounding variables and job components represents potential confounding; $\mathrm{H} 1$ - the relationship between on-site teaching and PA; $\mathrm{H} 2$ - the relationship between online teaching and PA; H3 - the relationship between research and PA; $\mathrm{H} 4$ - the relationship between

negative or non-significant among academics in a postCOVID-19 context for a couple of reasons. First, the relationship between PA and mental health, as depicted in Fig. 1, is linked to the job components, which means that the association between PA and mental health can be affected by the job components representing job demands in a social distancing context. Since academics would face an imbalance between job demands and resources and insufficient self-efficacy in a social distancing context, the PA-mental-health relationship could be negative. This relationship may be non-significant in contexts where the health benefits of PA from PAsupported job components (e.g., on-site teaching) is nullified by stress and psychological problems from COVID-19, or sedentary behavior from other job components (e.g., online teaching) offsets the mental health benefits of PA from PAsupported job components. That is, the relationship between PA and mental health can be different for academics who engage in both active and sedentary job tasks in a social distancing context where stress and related mental health declines are likely to be experienced. As shown in Fig. 1, therefore, non-directional hypotheses (H5-H8) representing the relationship between the job components and mental health were deemed appropriate for this study.

As Fig. 1 indicates, PA is a potential mediator of the relationship between the job components and mental health, but given the above arguments and theoretical deductions, PA may not benefit mental health in a post-COVID-19 period. To explain, PI from sedentary job demands (e.g., online teaching) can offset PA from other job demands involving physical activities (e.g., on-site teaching). In a situation where mental health struggles faced by academics due to COVID-19 are intense, PA can be student assessment and PA; H5 - the relationship between on-site teaching and mental health; H6 - the relationship between online teaching and mental health; $\mathrm{H} 7$ - the relationship between research and mental health; $\mathrm{H} 8$ - the relationship between student assessment and mental health; H9 - the relationship between PA and mental health

negatively associated with mental health because academics engaging in PA may already be facing mental health declines or struggles. From another perspective, PA knowledge and selfefficacy can predict high levels of PA that can overcome mental health declines, leading to a positive relationship between PA and mental health. With the above possibilities, a nondirectional hypothesis (H9) representing the relationship between PA and mental health was imperative. The mediation role of PA in Fig. 1 can be partial or complete. A partial mediation occurs if the job components are significantly associated with mental health and PA, while PA has a direct relationship with mental health (Richiardi et al., 2013). A complete or full mediation occurs if the job components do not have a significant relationship with mental health but are associated with PA, which in turn predicts mental health (Richiardi et al., 2013). A full mediation maximizes the importance of PA in the model because it connotes that the job components cannot affect mental health without PA. As Fig. 1 indicates, the relationship between the job components, PA, and mental health can be confounded by various personal variables. The next section details how these variables were selected and handled as confounding variables.

\section{Methods}

\section{Study Design and Design}

This study employed a cross-sectional design and an online questionnaire targeting academic staff of colleges of education, polytechnics, and universities. We gathered data using online surveys because the study was carried out at a time 
COVID-19 social distancing protocols were being implemented and observed.

\section{Research Population and Selection Process}

The study setting was countries where tertiary academic institutions reopened by August 31, 2020, and followed more stringent national social distancing protocols in their operational activities. The specific countries chosen were Nigeria, Ghana, Kenya, and Tanzania. The study population was academic staff of colleges, polytechnics and universities in these countries. Participants were selected with six inclusion criteria: (i) being a full-time academic; (ii) having worked as an academic for at least a year; (iii) having a minimum of a diploma, which we used as an indicator of the ability of a participant to read and write in English, the medium in which the questionnaire was administered; (iv) resumption of academic job duties after reopening of schools; (v) adherence to national and institutional social distancing measures; and (vi) willingness of the individual to participate. We did not use a powered sample or a sample computed based on available effect size and statistical power as no study with relevant statistics was available. Even so, recent COVID-19 studies used sample sizes between 50 and 4000 to produce useful findings (Asiamah et al., 2020; Elsahory et al., 2020). We, therefore, deemed a sample size of at least 1000 appropriate for this study.

\section{Structure of the Online Survey}

The online questionnaire was constructed by the researchers and hosted on Google Forms, a free online survey development and distribution software that allows data sharing between researchers. We preferred Google Forms to other related software because it is free of charge, flexible to use, and allows easy download or transfer of data. Because no default survey template was suited to this study, we developed the questionnaire from scratch. The survey was made up of five parts, with the first part comprising the first two questions. The first question comprised an ethics statement and survey completion instructions. The second question, which called for a "Yes" or "No" response, asked participants to indicate their willingness to voluntarily participate in the study. The second section of the survey comprised seven items measuring the core job components, namely online teaching, onsite teaching, research, and student assessment. Sections 3 and 4 measured mental health and PA respectively. Section 5 comprised 12 demographic variables, some of which were covariates. The "multiple questions per page" online questionnaire format was employed as the other formats (e.g. one question per page) would have made the survey too long. According to Sahlqvist et al. (2011), an excessively long survey can discourage participation and reduce questionnaire completion rate.

\section{Construction and Validation of the Online Survey}

To develop and validate the survey, we employed the robust procedure of Asiamah et al. (2020). After its validation, an online version of the revised questionnaire (including the ethics statement) was created by the second author and piloted online with 20 academics who were associates of the Africa Center for Epidemiology. Survey completion was done via WhatsApp (12 completed), email (4 completed), Facebook ( 2 completed), and LinkedIn ( 2 completed). The research team sent the final survey back to a group of experts (who were part of the original validation process) for approval after the pilot study showed that the questionnaire had no issues.

\section{Study Variables, Operational Definitions, and Coding Scheme}

We measured three main variables, namely the job components, mental health, and PA. Demographic characteristics were also measured as covariates. A 9-item Likert scale that was adopted from Lukat et al. (2016) was used to measure mental health. This scale is a unidimensional measure that recently produced a Cronbach's alpha coefficient $(\alpha) \geq 0.8$ on a Ghanaian sample (Asiamah et al., 2020). It has five anchors (i.e. strongly disagree; disagree; somewhat agree; agree; and strongly agree), and is considered a holistic measure of mental health (Lukat et al., 2016). In the current study, this measure produced a Cronbach's $\alpha$ value of 0.91 . The mental health index was calculated in harmony with Lukat et al. by adding up items of the scale. Appendix A shows items of the mental health scale. PA was measured with the short-form of the International Physical Activity Questionnaire (SF-IPAQ), which was used because it had produced satisfactory psychometric properties (i.e. reliability and validity) across the world (Lavelle et al., 2020; Oyeyemi et al., 2014; Wanner et al., 2016) and in Africa (Oyeyemi et al., 2014). In addition, its protocol for generating an index was the most convenient to us. In Table 1 is information regarding how the other variables were operationally defined, measured, and coded. All categorical variables captured as covariates were dummy-coded. Since confounding is not always possible (Asiamah et al., 2019), only variables evidenced in the literature to influence PA (Asiamah et al., 2020) or any of the job components (Hogan et al., 2016) were measured as covariates.

\section{Data Collection and Ethics}

After the study protocol was reviewed by the appropriate ethics review committee in Accra, the study was granted ethical clearance (Number 0022020ACE). As part of our ethical 
Table 1 Operationalization and coding of job components, participant characteristics, and covariates

\begin{tabular}{|c|c|c|c|c|}
\hline Variable & Indicator & Definition (operationalization) & Coding (values) & $\begin{array}{l}\text { Dummy- } \\
\text { coding }\end{array}$ \\
\hline \multirow[t]{11}{*}{$\begin{array}{l}\text { Participant } \\
\text { characteris- } \\
\text { tics }\end{array}$} & $\begin{array}{l}\text { University } \\
\text { classifica- } \\
\text { tion* }\end{array}$ & $\begin{array}{l}\text { Whether the individual's primary university } \\
\text { was a public, private, or hybrid academic } \\
\text { institution }\end{array}$ & Public (1), private (2), hybrid $* * * *(3)$ & Applied \\
\hline & Sex* & Reported gender of the participant & Male (0), female (1) & Applied \\
\hline & Country* & $\begin{array}{l}\text { The country where the participant was } \\
\text { working as a faculty member }\end{array}$ & $\begin{array}{l}\text { Nigeria (1), Ghana (2), Kenya (3), } \\
\text { Tanzania (4) }\end{array}$ & Applied \\
\hline & CDS* & $\begin{array}{l}\text { Whether the participant had at least one } \\
\text { clinically diagnosed chronic disease } \\
\text { condition }\end{array}$ & None $(0), \geq 1(1)$ & Applied \\
\hline & $\begin{array}{l}\text { Income } \\
\quad(\mathrm{USD}) * *\end{array}$ & $\begin{array}{l}\text { The faculty's gross monthly income in } \\
\text { United States Dollars }\end{array}$ & $\begin{array}{l}0-500(1), 501-1000(2), 1001-1500(3), \\
1501-2000(4), \text { Above } 2000(5)\end{array}$ & Not applied \\
\hline & $\operatorname{Rank}^{\mathrm{a}^{* *}}$ & The academic rank of the participant & $\begin{array}{l}\text { Teaching assistant (1), assistant lecturer (2), } \\
\text { lecturer (3), senior lecturer (4), assistant professor } \\
\text { (5), associate professor (6), full professor (7) }\end{array}$ & Not applied \\
\hline & Residency* & $\begin{array}{l}\text { Whether the faculty was resident on the } \\
\text { campus of his or her primary academic } \\
\text { institution }\end{array}$ & No $(0)$, Yes $(1)$ & Applied \\
\hline & Job tenure $* * *$ & $\begin{array}{l}\text { The number of years the participant had } \\
\text { served as an academic faculty }\end{array}$ & - & Not applied \\
\hline & $\begin{array}{l}\text { Alternative } \\
\operatorname{role}(s)^{*}\end{array}$ & $\begin{array}{l}\text { Whether the participant had other academic } \\
\text { job roles outside his/her primary academic } \\
\text { institution }\end{array}$ & No $(0)$, Yes (1) & Applied \\
\hline & $\begin{array}{l}\text { Educational } \\
\text { level*** }\end{array}$ & $\begin{array}{l}\text { The highest educational qualification acquired } \\
\text { by the academic }\end{array}$ & $\begin{array}{l}\text { Diploma (1), first degree (2), Master's } \\
\text { degree (3), PhD or equivalent (4) }\end{array}$ & Not applied \\
\hline & Age $(\mathrm{yrs}) * * *$ & The age of the academic in years & -. & Not applied \\
\hline Research & Research*** & $\begin{array}{l}\text { The amount of time the academic had spent } \\
\text { in the last } 7 \text { days on research-related } \\
\text { activities }\end{array}$ & $\cdots$ & Not applied \\
\hline \multirow[t]{2}{*}{ Teaching } & $\begin{array}{l}\text { Teaching } \\
\text { online*** }\end{array}$ & $\begin{array}{l}\text { The time spent by the academic on online } \\
\text { teaching over the last } 7 \text { days }\end{array}$ & $\ldots$ & Not applied \\
\hline & $\begin{array}{l}\text { Teaching } \\
\text { onsite*** }\end{array}$ & $\begin{array}{l}\text { The time spent by the academic on teaching } \\
\text { in a physical classroom over the last week }\end{array}$ & $\cdots$ & Not applied \\
\hline \multirow[t]{4}{*}{$\begin{array}{l}\text { Student } \\
\text { assessment }\end{array}$} & Marking*** & $\begin{array}{l}\text { The amount of time spent by the academic } \\
\text { on marking of examination/test scripts } \\
\text { over the last week }\end{array}$ & $\cdots$ & Not applied \\
\hline & $\begin{array}{l}\text { Marks } \\
\text { organiza- } \\
\text { tion*** }\end{array}$ & $\begin{array}{l}\text { The amount of time spent by the academic } \\
\text { on organizing test/examination scores } \\
\text { over the last week }\end{array}$ & $\cdots$ & Not applied \\
\hline & $\begin{array}{l}\text { Quizzes and } \\
\text { exams*** }\end{array}$ & $\begin{array}{l}\text { The amount of time the academic spent on } \\
\text { conducting quizzes and examinations } \\
\text { over the last week }\end{array}$ & $\ldots$ & Not applied \\
\hline & $\begin{array}{l}\text { Project } \\
\text { supervi- } \\
\text { sion*** }\end{array}$ & $\begin{array}{l}\text { The amount of time spent by the academic } \\
\text { on student research project supervision over } \\
\text { the last week }\end{array}$ & $\ldots$ & Not applied \\
\hline
\end{tabular}

\footnotetext{
${ }^{*}$ Nominal variable; ${ }^{* *}$ Ordinal variable; ${ }^{* * *}$ Continuous variable; ${ }^{* * * *}$ An institution with public and private ownership status; ${ }^{--}$Not applicable; ${ }^{\text {a }}$ Each category was associated with its research specialization; CDS - chronic disease status
}

measures, we ensured that only volunteers participated in the study. The survey's first question stated the risk-free nature of the data collection procedure and the significance of the study. The survey also included the study's inclusion criteria and assured respondents that their participation in the study was anonymized. We published the online survey on October 10, 2020 by sending them to different groups on social media that included or comprised academics. The survey's link was shared on four WhatsApp and Telegram group pages owned by the Africa Center for Epidemiology. These platforms comprised academics of all ranks as well as students undertaking research studies in different African universities. A total of 11 nationalities were in the groups, though the majority of members were from Ghana, Nigeria, Tanzania, and Kenya. The four groups contained a total of 361 scholars and postgraduate students as of October 10,2020. With members serving as the first contact persons, we employed the snowball selection process applied by Asiamah et al. (2020) to distribute the survey. 
Members who met the selection criteria were implored to complete the online survey and forward it to colleagues and other academics in their countries and academic institutions. Information on how to distribute the questionnaire was shared on the platforms for a week in an effort to guide members to distribute the survey. Further to this, all researcher collaborators distributed the questionnaire by sharing its link on their faculty platforms. The short link of the survey took the participants to a pop-up survey that could be filled and completed with a relatively weak internet network. Participants were not required to download the survey before completing it. The questionnaire was distributed over 4 weeks and closed on November 15,2020 . The average survey completion rate was about $5 \mathrm{~min}$. We avoided multiple responses by programming the survey appropriately in Google Forms. We did not provide incentives to participants.

\section{Methods of Statistical Analysis}

The data, in a default MS Excel file, were downloaded from Google Forms and transported to version 25 of SPSS (i.e. Statistical Package for the Social Sciences) where coding and data analysis were carried out. The version of SPSS used had an in-built Amos software, which we used to conduct the mediation analysis. Summary (descriptive) statistics were generated to assess the distribution of the data after 14 questionnaires with missing data were dropped in line with previous practices (Garson, 2012; Asiamah et al., 2020). It was necessary to remove questionnaires with missing data because structural equation modeling (SEM), which was used for the mediation analysis, does not support missing data (Garson, 2012). Multivariate normality of the data, which is a requirement for the use of SEM, was assumed and assessed with the SEM. The probability ( $p$ ) values of the Mahalanobis distance test from this assessment met the condition $p \geq 0.05$ (Garson, 2012) and, therefore, evidenced multivariate normality of the data. We adopted the following standard formula from Lavelle et al. (2020) to produce the PA index:

$$
\begin{aligned}
& \text { Total MET-minutes/week } \\
& \begin{aligned}
= & \text { Walking }(\text { MET*min*days }) \\
& + \text { Moderate PA }(\text { MET*min*days) } \\
& + \text { Vigorous PA (MET*min*days) }
\end{aligned}
\end{aligned}
$$

In the above equation, MET is an acronym for Metabolic Equivalent whereas walking, moderate, and vigorous PA are the dimensions of the IPAQ (short form). The MET values assigned to these three dimensions are walking $=3.3$, moderate $\mathrm{PA}=4$, and vigorous $\mathrm{PA}=8$.

As part of the exploratory analysis, we conducted a sensitivity analysis recently applied by Asiamah et al. (2020) to identify the ultimate covariates for the final regression models. The ultimate variables in this context are variables that could significantly affect the primary relationships. In the first phase of this analysis, we developed an index of the job components and fitted univariate regression to compute crude weights representing the influence of the resulting index on mental health. At this phase, variables that meet the criterion $p \leq 0.25$ were retained for the second phase. Country, rank, residency, and CDS (chronic disease status) were removed at this stage. At the second phase, a multiple linear regression model was fitted to estimate the effects of the job components and covariates from stage 1 on mental health. Covariates that led to a $10 \%$ increase or decrease in the effects between the job components and mental health were incorporated into the ultimate model as the ultimate covariates. Sex, tenure, and income were the ultimate covariates selected at the second stage. Furthermore, we conducted a statistical assessment of common methods bias (CMB) that may have resulted from our use of cross-sectional data. In this vein, we employed the Harman's one-factor test, the most widely used statistical technique for assessing $\mathrm{CMB}$, to examine our data (Podsakoff et al., 2003; Jordan \& Troth, 2020). This method is about using exploratory factor analysis to assess the factor structure of standard scales used to gather data, and observing the factor solution reached (Jordan \& Troth, 2020). CMB is absent if a 2 or more factor-solution is produced by the analysis. Though relatively short, the mental health scale used produced a 3-factor solution, with its items producing factor loadings $\geq 0.5$. With this result, relevant criteria that indicate the absence of $\mathrm{CMB}$ were met (Podsakoff et al., 2003).

In the main analysis, the baseline model was fitted to estimate the direct influences of the four job components and their indirect influences (through PA) on mental health. This model did not include the ultimate confounding variables. A second model, the ultimate model, tested the same primary relationships as the baseline model but included the ultimate covariates. By comparing the two models, we demonstrated the roles of the covariates in the ultimate model, which was the source of the final results. In harmony with best practices reported (Andreassen et al., 2018; Asiamah et al., 2019), we assessed the mediating role of PA in the models by estimating the indirect influences of the job components on mental health. To assess the significance of the covariates, the relative fits of the two SEM models were compared 
Table 2 Descriptive statistics summarizing participant characteristics

\begin{tabular}{|c|c|c|}
\hline Variable & Group & $n(\%)$ \\
\hline \multirow[t]{6}{*}{ Income (USD) } & $0-500$ & $192(18.0)$ \\
\hline & $501-1000$ & $388(36.5)$ \\
\hline & $1001-1500$ & $224(21.1)$ \\
\hline & $1501-2000$ & $96(9.0)$ \\
\hline & Above 2000 & $164(15.4)$ \\
\hline & Total & $1064(100)$ \\
\hline \multirow[t]{5}{*}{ Educational level } & Diploma & $16(1.5)$ \\
\hline & First degree & $76(7.1)$ \\
\hline & Master's degree & $480(45.1)$ \\
\hline & $\mathrm{PhD}$ or equivalent & $492(46.2)$ \\
\hline & Total & $1064(100)$ \\
\hline \multirow[t]{3}{*}{ Sex } & Male & $720(67.7)$ \\
\hline & Female & $344(32.3)$ \\
\hline & Total & $1064(100)$ \\
\hline \multirow[t]{3}{*}{ Alternative role(s) } & No & $624(58.6)$ \\
\hline & Yes & $440(41.6)$ \\
\hline & Total & $1064(100)$ \\
\hline \multirow[t]{3}{*}{ Campus residency } & No & $880(82.7)$ \\
\hline & Yes & $184(17.3)$ \\
\hline & Total & $1064(100)$ \\
\hline \multirow[t]{5}{*}{ Country } & Ghana & $372(35.0)$ \\
\hline & Nigeria & $400(37.6)$ \\
\hline & Kenya & $272(25.6)$ \\
\hline & Tanzania & 20(1.9) \\
\hline & Total & $1064(100)$ \\
\hline \multirow[t]{3}{*}{ Chronic disease status } & None & $836(78.6)$ \\
\hline & $\geq 1$ & $228(21.4)$ \\
\hline & Total & $1064(100)$ \\
\hline \multirow[t]{4}{*}{ University classification } & Public & $760(71.4)$ \\
\hline & Private & $280(26.3)$ \\
\hline & Hybrid (public and private) & $24(2.3)$ \\
\hline & Total & $1064(100)$ \\
\hline \multirow[t]{7}{*}{$\operatorname{Rank}^{* *}$} & Teaching assistant & $96(9)$ \\
\hline & Assistant lecturer & 192(18) \\
\hline & Lecturer & $380(35.7)$ \\
\hline & Senior lecturer & $248(23.2)$ \\
\hline & Associate professor & $76(7.1)$ \\
\hline & Professor (full) & $72(6.8)$ \\
\hline & Total & $1064(100)$ \\
\hline
\end{tabular}

** Each category was associated with its research specialization; $\mathrm{n}-$ frequency, USD - United States

based on the Akaike Information Criterion (AIC) in line with previous practices (Asiamah \& Danquah, 2019). Statistical significance of the result was detected at $p<0.05$.

\section{Findings}

\section{Descriptive and Correlational Analysis}

A total of 1064 surveys out of 1201 completed were analyzed after applying the selection criteria and removing missing items in line with Garson (2012). Tables 2 and 3 show key summary statistics on the variables. In Tables 2 , $35 \%(n=372)$ of academics were from Ghana, $38 \%(n=$ $400)$ were from Nigeria, $26 \%(n=272)$ were from Kenya, and 2\% $(n=20)$ were from Tanzania. About $68 \%(n=720)$ of the academics were men whereas $32 \%(n=344)$ were women. In Table 3, the average age and PA level of participants were about 44 years and 4475 MET-minutes/ week respectively. The average mental health score was about 32 (Mean = 31.51; SD=7.21). Mental health was positively correlated with PA $(r=0.351, p=0.000$; twotailed), which suggests that mental health increases as PA increases. Mental health was also positively correlated with teaching onsite $(r=0.178, \mathrm{p}=0.000$; two-tailed) but negatively correlated with teaching online $(r=-0.19 ; \mathrm{p}=$ 0.000 ; two-tailed), research $(r=-0.457 ; \mathrm{p}=0.000$; twotailed), and student assessment $(r=-0.438 ; \mathrm{p}=0.000$; two-tailed). This result connotes that mental health increases with onsite teaching but reduces with the other three job components. PA was negatively correlated with research $(r=-0.748 ; \mathrm{p}=0.000$; two-tailed $)$ and student assessment ( $r=-0.779 ; \mathrm{p}=0.000$; two-tailed), implying that PA reduces as research and student assessment increase. PA is positively correlated with teaching onsite $(r=0.064$, $\mathrm{p}<0.05$; two-tailed), though this relationship is weak.

\section{Analysis of Primary Relationships}

In Table 4, research has a positive relationship with PA ( $\beta=$ $0.15 ; t=2.02 ; \mathrm{p}<0.05)$ while student assessment $(\beta=-0.83$; $t=-11.36 ; \mathrm{p}=0.000$ ) has a negative relationship with PA in the ultimate model. It is thus found that PA increases with research but reduces with student assessment. Teaching onsite has a positive relationship with mental health $(\beta=0.12 ; t=$ $4.95 ; \mathrm{p}=0.000)$, but the associations between teaching online $(\beta=-0.13 ; t=-5.05 ; \mathrm{p}=0.000)$ and research $(\beta=-0.57 ; t=$ $-5.42 ; p=0.000)$ with mental health are negative. These results indicate that mental health improves with onsite teaching but reduces with online teaching and research. Student assessment and PA have no significant relationship with mental health. None of the indirect effect estimates is significant, which means that PA did not mediate the relationships between the job components and mental health. Table 5 shows the fit statistics of the baseline and ultimate models. The table also contains standard criteria that a model with satisfactory fit should meet (Asiamah \& Danquah, 2019). Both models met the recommended criteria, but the ultimate model produced a 
Table 3 Pearson's correlation between physical activity, job components, mental health, and ultimate covariates $(n=1064)$

\begin{tabular}{|c|c|c|c|c|c|c|c|c|c|c|c|c|}
\hline Variable & $\#$ & Mean & SD & 1 & 2 & 3 & 4 & 5 & 6 & 7 & 8 & 9 \\
\hline Teaching online & 1 & 5.33 & 4.23 & 1 & $-.231 * *$ & 0.047 & 0.048 & $-.190 * *$ & -0.048 & -0.015 & -0.006 & $-.069 *$ \\
\hline Teaching onsite & 2 & 5.95 & 4.94 & & 1 & -0.033 & -0.055 & $.178 * *$ & $.064 *$ & $-.102 * *$ & -0.035 & $-.078 *$ \\
\hline Research & 3 & 2.33 & 1.1 & & & 1 & $.972 * *$ & $-.457 * *$ & $-.748 * *$ & $.102 * *$ & 0.038 & -0.035 \\
\hline Assessment & 4 & 6.95 & 3.22 & & & & 1 & $-.438 * *$ & $-.779 * *$ & $.094 * *$ & 0.054 & -0.039 \\
\hline Mental health & 5 & 31.51 & 7.21 & & & & & 1 & $.351 * *$ & -0.057 & $.075^{*}$ & 0.053 \\
\hline Physical activity & 6 & 4475.305 & 2754.33 & & & & & & 1 & $-.127 * *$ & $-.067^{*}$ & 0.054 \\
\hline $\operatorname{Sex}^{\mathrm{a}}$ & 7 & - & - & & & & & & & 1 & -0.03 & 0.031 \\
\hline Income (USD) & 8 & - & - & & & & & & & & 1 & $.132 * *$ \\
\hline Job tenure & 9 & 9.83 & 6.197 & & & & & & & & & 1 \\
\hline
\end{tabular}

${ }^{* *} p<0.001 ;{ }^{*} \mathrm{p}<0.05 ;{ }^{\mathrm{a}}$ reference - male; SD - standard deviation; USD - United States Dollars; - Not applicable

smaller Akaike Information Criterion (AIC) and was, therefore, of a higher fit. Thus, both models were of satisfactory fit.

\section{Discussion}

This study aimed to examine the association between core academic job components, PA, and mental health. The potential mediating influence of PA in the relationship between the job components and mental health was also evaluated. Five of the 9 non-directional hypotheses tested (i.e., H3, H4, H5, H6, and H7) were supported by our data.

This study found a positive relationship between research work and PA, which indicates that PA improves as research increases among academics. Research among academics has two main components, fieldwork and desk research, with the latter involving sedentary tasks such as reading and writing (Torp et al., 2017; Torp et al., 2018). Research work can, therefore, be expected to increase PI if focused on the foregoing sedentary tasks. In contrast, fieldwork involves social engagement with research participants and is, thus, likely to encourage walking and other physical activities. A positive relationship between research work and PA is, in effect, an indicator of the PA-driven nature of fieldwork and research involving less sitting in a post-COVID-19 context. Further to this, academics in the post-COVID-19 situation may have carried out more fieldwork involving physical activities, possibly because most of them had a backlog of field research tasks to perform or supervise at the time schools reopened. The inability of academics to undertake field research due to social distancing measures rolled out until the third quarter of 2020 may have led to the said backlog. This reasoning is congruent with the argument of Yankholmes (2014) that the growing "publish or perish" culture in Africa obliges academics to constantly undertake research. As such, academics may have hurried up to clear research backlogs in the way of data collection and other PA-oriented research activities at the time of reopening. What could be inferred from the above thoughts is that a negative association between research and PA can be the result of occupational sitting necessitated by sedentary research tasks (i.e. reading, literature review, and writing). In the light of this understanding, our findings suggest that academics did little of sedentary or desk research after schools reopened.

Data analysis supports a negative relationship between student assessment and PA, which suggests that PA decreases as time spent on the assessment of students increases. This outcome of the study is congruent with some observations reported in the literature (Egan et al., 2019; Booket et al., 2018), including Hogan et al.'s (2016) description of student assessment as a sedentary job component among academics. In harmony with our result, Egan et al. (2019) insinuated that marking of examination or test scripts and organization of test results from this exercise require a significant sedentary time. Further to the above, Booket and associates (2018) reasoned that examination supervision or invigilation involves walking at a low pace or prolonged sitting, which indicates that invigilation can also be sedentary. Arguably, script marking and marks organization are more sedentary than invigilation as they can only be performed while the individual is sitting. From the perspective of Hogan et al. (2016), an aspect of student assessment that could have encouraged PA is the supervision of internships and student fieldwork. In the postCOVID-19 context however, academics in Africa did not conduct field assessment because students were observing social isolation and were not serving as interns (Muhumuza \& Odula, 2020; Harrington \& O'Reilly, 2020). We, therefore, decided not to measure and incorporate field assessment in this study, though future studies may have to consider it. Given our evidence and the foregoing arguments, it is possible that student assessment involving invigilation, marking, and organization of test or examination results in the post-COVID19 context is largely sedentary and, as a result, has a negative association with PA. As opined by Harrington and O'Reilly 
Table 4 The association between core job components, PA, mental health, and covariates

\begin{tabular}{|c|c|c|c|c|c|c|c|c|c|}
\hline \multirow[t]{2}{*}{ Model } & \multirow{2}{*}{$\begin{array}{l}\text { Dependent } \\
\text { variable }\end{array}$} & \multirow[t]{2}{*}{ Path } & \multirow[t]{2}{*}{ Predictor } & \multicolumn{4}{|c|}{ Direct coefficients } & \multicolumn{2}{|l|}{ Indirect coefficients } \\
\hline & & & & $\begin{array}{l}\text { Unstandardized } \\
\text { (B) }\end{array}$ & $\begin{array}{l}\text { Standardized } \\
(\beta)\end{array}$ & $\begin{array}{l}\text { Std. Error (of } \\
\text { B) }\end{array}$ & $\begin{array}{l}\text { Critical } \\
\text { ratio }\end{array}$ & $\begin{array}{l}\text { Unstandardized } \\
\text { (B) }\end{array}$ & $\begin{array}{l}\text { Standardized } \\
(\beta)\end{array}$ \\
\hline \multirow[t]{9}{*}{$1^{\mathrm{a}}$} & Physical activity & $<--$ & $\begin{array}{l}\text { Teaching } \\
\text { (on-line) }\end{array}$ & -4.87 & -0.01 & 12.86 & -0.38 & - & - \\
\hline & Physical activity & $<--$ & $\begin{array}{l}\text { Teaching } \\
\text { (on-site) }\end{array}$ & 9.24 & 0.02 & 11.05 & 0.84 & - & - \\
\hline & Physical activity & $<---$ & Research & 417.80 & 0.17 & 207.32 & $2.02 *$ & - & - \\
\hline & Physical activity & $<---$ & Assessment & -805.01 & -0.94 & 70.87 & $-11.36^{* *}$ & - & - \\
\hline & Mental health & $<--$ & $\begin{array}{l}\text { Teaching } \\
\text { (on-line) }\end{array}$ & 0.20 & 0.04 & 0.12 & $4.95 * *$ & - & - \\
\hline & Mental health & $<--$ & $\begin{array}{l}\text { Teaching } \\
\text { (on-site) }\end{array}$ & -0.23 & 0.05 & -0.13 & $-5.05 * *$ & - & - \\
\hline & Mental health & $<---$ & Research & -4.07 & 0.75 & -0.57 & $-5.42 * *$ & - & - \\
\hline & Mental health & $<---$ & Assessment & 0.45 & 0.27 & 0.18 & 1.66 & - & - \\
\hline & Mental health & $<--$ & $\begin{array}{l}\text { Physical } \\
\text { Activity }\end{array}$ & 0.00 & 0.00 & 0.03 & 0.66 & - & - \\
\hline \multirow[t]{22}{*}{$2^{b}$} & Physical activity & $<--$ & $\begin{array}{l}\text { Teaching } \\
\text { (on-line) }\end{array}$ & -4.87 & -0.01 & 12.86 & -0.38 & - & - \\
\hline & Physical activity & $<---$ & $\begin{array}{l}\text { Teaching } \\
\text { (on-site) }\end{array}$ & 9.24 & 0.02 & 11.05 & 0.84 & - & - \\
\hline & Physical activity & $<---$ & Research & 417.80 & 0.15 & 207.32 & $2.02 *$ & - & - \\
\hline & Physical activity & $<--$ & Assessment & -805.01 & -0.83 & 70.87 & $-11.36 * *$ & - & - \\
\hline & Mental health & $<---$ & $\begin{array}{l}\text { Teaching } \\
\text { (on-site) }\end{array}$ & 0.20 & 0.12 & 0.04 & $4.95 * *$ & 0.000 & 0.000 \\
\hline & Mental health & $<--$ & $\begin{array}{l}\text { Teaching } \\
\quad \text { (on-line) }\end{array}$ & -0.23 & -0.13 & 0.05 & $-5.05 * *$ & 0.000 & 0.000 \\
\hline & Mental health & $<---$ & Research & -4.07 & -0.57 & 0.75 & $-5.42 * *$ & -0.310 & 0.004 \\
\hline & Mental health & $<---$ & Assessment & 0.45 & 0.18 & 0.27 & 1.66 & -0.059 & -0.024 \\
\hline & Mental health & $<--$ & $\begin{array}{l}\text { Physical } \\
\text { activity }\end{array}$ & 0.00 & 0.03 & 0.00 & 0.66 & - & - \\
\hline & Covariates & & & & & & & & \\
\hline & $\begin{array}{l}\text { Teaching } \\
\text { (on-line) }\end{array}$ & $<--$ & Income (USD) & -0.11 & -0.03 & 0.12 & -0.93 & - & - \\
\hline & $\begin{array}{l}\text { Teaching } \\
\text { (on-site) }\end{array}$ & $<---$ & Income (USD) & 0.01 & 0.00 & 0.10 & 0.09 & - & - \\
\hline & Research & $<---$ & Income (USD) & 0.04 & 0.05 & 0.03 & 1.53 & - & - \\
\hline & Assessment & $<---$ & Income (USD) & 0.16 & 0.06 & 0.08 & $2.05^{*}$ & - & - \\
\hline & $\begin{array}{l}\text { Teaching } \\
\text { (on-line) }\end{array}$ & $<---$ & Tenure & -0.05 & -0.07 & 0.02 & $-2.24 *$ & - & - \\
\hline & $\begin{array}{l}\text { Teaching } \\
\text { (on-site) }\end{array}$ & $<---$ & Tenure & -0.06 & -0.07 & 0.02 & $-2.31^{*}$ & - & - \\
\hline & Research & $<--$ & Tenure & -0.01 & -0.04 & 0.01 & -1.43 & - & - \\
\hline & Assessment & $<---$ & Tenure & -0.03 & -0.05 & 0.02 & -1.62 & - & - \\
\hline & $\begin{array}{l}\text { Teaching } \\
\text { (on-line) }\end{array}$ & $<---$ & $\operatorname{Sex}^{\mathrm{c}}$ & -0.12 & -0.01 & 0.28 & -0.43 & - & - \\
\hline & $\begin{array}{l}\text { Teaching } \\
\text { (on-site) }\end{array}$ & $<---$ & $\operatorname{Sex}^{\mathrm{c}}$ & -1.06 & -0.10 & 0.32 & $-3.30 * *$ & - & \\
\hline & Research & $<---$ & $\mathrm{Sex}^{\mathrm{c}}$ & 0.25 & 0.10 & 0.07 & $3.42 * *$ & - & \\
\hline & Assessment & $<---$ & $\operatorname{Sex}^{\mathrm{c}}$ & 0.67 & 0.10 & 0.21 & $3.19^{*}$ & - & \\
\hline
\end{tabular}

${ }^{*} \mathrm{p}<0.05 ;{ }^{* *} \mathrm{p}<0.001 ;{ }^{\mathrm{a}}$ baseline model without covariates; ${ }^{\mathrm{b}}$ ultimate model with covariates; ${ }^{\mathrm{c}}$ reference - male; USD - United States Dollars; - Not applicable

(2020), the negative relationship between PA and student assessment may also have been due to the replacement of physical classroom invigilation with online student assessment, mentoring, and engagement. 
Table 5 Model fit indices for the structural models and recommended criteria

\begin{tabular}{lrrrrrrr}
\hline Model & $\begin{array}{l}\text { Chi- } \\
\text { square }\end{array}$ & $\mathrm{p}$ & RMSEA & TLI & GFI & AGFI & AIC \\
\hline Baseline & 2.088 & 0.109 & 0.044 & 0.977 & 0.968 & 0.989 & 41.88 \\
Ultimate & 2.910 & 0.099 & 0.049 & 0.971 & 0.961 & 0.980 & 38.02 \\
Recommended criteria & $\leq 3$ & $\geq 0.05$ & $\leq 0.08$ & $\geq 0.95$ & $\geq 0.9$ & $\geq 0.9$ & - \\
\hline
\end{tabular}

IIRMSEA random mean square error of approximation, TLI Tucker-Lewis Index, GFI goodness-of-fit indices, $A G F I$ adjusted goodness-of-fit indices, AIC Akaike Information Criterion; - Model with a smaller AIC is of higher fit
Our results indicate that not all the academic job components have a positive relationship with PA; research and student assessment had contrasting relationships with PA. The failure of online teaching and on-site teaching to predict PA may be unique to the post-COVID-19 context or could be due to our study design, which requires future replications of this study in similar contexts using experimental designs that maximize internal validity. Yet, the relationship found between research, student assessment, and PA demonstrates the applicability of the JD-R theory, at least from the perspective of our theoretical framework, to explain the relationship between academic job components and PA. Suffice it to say that academic tasks, which the JD-R theory recognizes as job demands, affect the individuals PA depending on how much of sedentary behavior and physical activities (e.g., walking) these tasks require. These could be so because job demands require academics to adhere to some standard methods and guidelines in teaching, which means that academics cannot significantly change every aspect of a job task. For instance, online teaching often requires immobility and makes it impossible for the tutor to have physical interactions with students. On the other hand, on-site teaching always requires instructing students in a classroom where physical class activities can be performed. Hence, work-related PA and sedentary behavior are tied to job demands. According to the HBM, resources such as PA knowledge, physical functional capacity, and self-efficacy can encourage PA that compensate for jobrelated PI and maximize PA from academic work. Thus, PA voluntarily performed in the post-COVID-19 context due to resources such as PA knowledge and self-efficacy (Asiamah et al., 2020) did not render the relationship between sedentary job tasks (i.e., student assessment) and PA positive or nonsignificant.

Teaching onsite was found to be positively associated with mental health, suggesting that mental health in academics increases as onsite teaching increases. A key implication of this result is that onsite teaching in a post-COVID-19 context buffered mental health declines and struggles despite social distancing measures observed by academics. Similarly, teaching in a physical classroom setting requires walking, standing, and similar campus-based physical activities that could not be completely avoided even in a post-pandemic situation requiring the observance of institutional and national social distancing measures. These ideas relate to our adaptation of the JD-R theory, which suggests that job tasks are demands that academics have little control over in a post-COVID-19 context; PA-supporting job tasks would reduce stress and related psychological problems whereas sedentary tasks would support these problems. If on-site teaching, in the face of sedentary job tasks such as online teaching, was positively associated with mental health, then PI and sedentary behavior from work could not outplay the influences of walking and physical activities associated with on-site teaching on health. This may be owing to additional voluntary PA performed off the job with available resources such as PA knowledge, selfefficacy, and social support. According to some recent studies (Harrington \& O’Reilly, 2020; Aperribai et al., 2020; Varea \& González-Calvo, 2020), access to campus facilities (e.g. shops, cafeteria, lounges, etc.) and social networks comprising students and colleagues may have enabled academics to secure social and emotional support and participate in social activities while observing social distancing protocols. Research has evidenced that social support and activities have a positive association with mental health in the general population including academics (Benedetti et al., 2008; Hamer et al., 2009; Peluso \& de Andrade, 2005; Veroma et al., 2017; Aperribai et al., 2020). Similarly, a meta-analytic review conducted by Fasihi Harandi et al. (2017) found that mental health was positively associated with social support in the general population. In China, Sun et al. (2020) found a positive association between social support and psychological health, which is an indicator of mental health. Finally, Min et al. (2016) found that social activities were associated with lower mental health risks, including the risk of depression.

Teaching online had a negative association with mental health, which affirms that mental health decreases as research work increases. This evidence implies that PA performed within the period on and off the job could not outplay sedentary behavior from online teaching and render its association with mental health positive or non-significant. It also supports the idea that online teaching is largely sedentary and can include several hours of occupational sitting, which is a major risk factor for mental health struggles and conditions 
(Aperribai et al., 2020; Asiamah et al., 2020). Further to this, Picavet et al. (2016) in the Netherlands found that occupational sitting was associated with poor mental health. This evidence was affirmed in the same context by Proper et al. (2012) and in some African contexts (Simons et al., 2013). These pieces of evidence complement several other commentaries (Lindsay et al., 2016; Mackenzie et al., 2015; Picavet et al., 2016; Proper et al., 2007) indicating that health risks including mental health declines are associated with occupational sitting and PI. Though positively associated with PA, research was found to have a negative association with mental health, which indicates that an increase in research work decreases mental health in academics. This result can be explained from two perspectives. Firstly, academics who reported larger PA scores were not necessarily active since PA and sedentary behavior are independent behaviors and can have independent influences on health outcomes (Dogra et al., 2012). In a post-COVID-19 situation, even academics who reported larger PA scores were possibly sedentary owing to social distancing measures taken by them and their involvement in other sedentary job tasks. Such academics can experience a decline in mental health associated with sedentary behavior and social disruptions from COVID-19. More so, mental health is affected by several socio-economic factors (e.g. current financial situation) as well as co-morbidities that may interact with sedentary behavior to reduce mental health in a post-COVID-19 context.

Though positively correlated with mental health as shown in Table 3, PA was not significantly associated with mental health in the ultimate regression models. This result may be due to a strong negative association between PA and student assessment, which has the tendency of neutralizing the positive correlation (in Table 3) between PA and mental health. Suffice it to say that PA would not predict mental health if it is strongly reduced by student assessment, as the case is in the ultimate regression model. Drawing on a recent commentary on the behavior of predictors in multiple linear regression (Lindner et al., 2019), we reason that the association between PA and mental health in Table 3 reduced and became non-significant in the regression model because student assessment withdrew its influence on PA in the regression model. Since sedentary behavior is the ideal cause of the negative association between PA and student assessment, a lack of a significant relationship between PA and mental health connotes that sedentary tasks can offset the moderate and weak influences of PA-oriented job tasks such as onsite teaching in a post-COVID-19 context. This thinking is consistent with several studies that have theorized that PI and sedentary behavior can counteract the beneficial impacts of PA on health indicators (Dogra et al., 2012). Some studies (Dogra et al., 2012; Asiamah et al., 2020) have observed that it is this potential of PI and sedentary behavior to neutralize the effect of PA on health that makes it necessary for individuals to completely avoid sedentary behavior.

Needless to say, a lack of a significant association between PA and mental health in a post-COVID-19 context explains why PA did not mediate the relationship between any of the job components and mental health. What could be inferred from this result is that even PA-oriented job components may not support health outcomes, specifically mental health, in a post-COVID-19 situation where academics concurrently carry out sedentary and PA-oriented tasks while complying with social distancing measures. If so, on-site teaching and other PA-driven job roles may not benefit mental health and possibly other health indicators in a post-COVID-19 context. Drawing on the discussions presented early on, it is understandable that PA in the post-COVID-19 context did not benefit mental health for three reasons. First, stress and other mental health struggles were possibly high and could not be buffered by PA. Second, resources such as PA knowledge and self-efficacy could not optimize PA to buffer psychological problems and increase mental health. Finally, the opposite influences of sedentary and PA-supporting tasks on PA could nullify the potential incremental influence of PA on health. If so, interventions are needed to maximize PA and discourage sedentary behavior in academics, particularly in a postCOVID-19 setting. Potential interventions may include the rolling out of health education programs that maximize academics' awareness of the risk factors such as PI and sedentary behavior. Such an educational program is necessary for even an elite population that may undermine healthy behaviors (e.g., PA, exercise) due to their constant preoccupation with employment-related tasks. In congruence with universities in developed countries such as the UK (George et al., 2014), African universities can provide PA facilities on campus to facilitate active behaviors in faculties, students and administrative staff. Universities can also support their staff to enroll in online Pilates classes, which have been evidenced to reduce PI and sedentary behavior during COVID-19 lockdowns (Nyenhuis et al., 2020).

Worth adding is a couple of implications of our findings for theory and research. First of all, a lack of a significant association between PA and mental health in a post-COVID-19 setting means that a pandemic and other socioenvironmental factors (e.g. violence, social distrust, social segregation, extreme climate change events) that can cause social disengagement at the population level are likely to deprive communities and individuals of the health benefits of PA. From this standpoint, PA does not necessarily contribute to the improvement of mental health and possibly other health outcomes if social isolation is necessitated by social distancing measures and extreme events such as floods, landslides, and violence. Moreover, our findings provide a basis for understanding the relationship between academic work, PA, and 
mental health. This understanding concerns how job demands (from the perspective of the JD-R theory) in the form of changes in work patterns in a post-COVID-19 context necessitate both PA and PI. Job demands that require more sedentary behavior (e.g., student assessment) is negatively associated with PA, whereas those that involve more walking and other physical activities are positively associated with PA. From the viewpoint of the HBM, therefore, sedentary behavior from student assessment and other sedentary tasks can be compensated for or reduced with voluntary PA performed off the job in the light of one's PA knowledge, self-efficacy, and other resources available. In situations where resources are unavailable or insufficient, then voluntary PA performed off the job is not possible, so PI can offset the benefits of PA. At worse, PI would outplay PA, resulting in health problems such as mental health declines. Deductively, universities need to develop and implement policies that promote job-related PA and reduce occupational PI. In the light of these policies, health education programs that provide PA knowledge and interventions aimed at enhancing campus walkability can be rolled out. As indicated early on, the provision of sporting facilities on campus alongside guidelines encouraging the use of these facilities can encourage engagement in PA.

This study has some strengths and limitations. First of all, the cross-sectional design employed is not robust against confounding, which means that this study could not establish causation between the variables. The implication of this limitation is reversibility of the supported relationships. For instance, a positive relationship between research and PA may represent a situation where PA increases as research time increases. The positive relationship between on-site teaching and mental health may also represent a situation where on-site teaching time increases as mental health increases. Researchers are, therefore, encouraged to apply randomized controlled designs in future. Secondly, it was impossible to apply a powered sample in this study due to our utilization of an online survey. For this reason, our study sample is not necessarily representative of all academics, so future researchers are encouraged to apply powered or representative samples. Despite this limitation, our sample was relatively large and came from a relatively wide geographical setting of four African countries. Our results can, therefore, be representative of African academics, at least. Moreover, our sensitivity analysis enabled us to reduce confounding as much as possible and demonstrate a resilient statistical technique for identifying ultimate covariates. By this sensitivity analysis, therefore, the current study guides researchers to adjust for potential covariates and eliminate irrelevant covariates that could disrupt primary predictors in a regression model. This contribution was based on the idea that over- or under-adjustment of regression models in cross-sectional designs to avoid or reduce confounding is as unscientific as failing to control for covariates in such models (Asiamah et al., 2019). Last but not least, this study did not include some academic job components (e.g., administrative work and industry engagement) whose measurement was problematic in the post-COVID-19 context.

\section{Conclusions}

Physical activity increases with research but reduces with student assessment, which suggests that student assessment is associated with a high risk of sitting and other sedentary behaviors in a post-COVID-19 context. Mental health increases with onsite teaching but reduces with online teaching and research, suggesting that mental health is more likely to increase with increasing onsite teaching but would reduce with increasing research and online teaching activities in a postCOVID-19 context. Interestingly, PA and mental health are not significantly associated, though a moderate correlation exists between them. PA does not mediate the relationship between the core job components and mental health. The ultimate model is of a better fit, which implies that the incorporation of the covariates in the ultimate model resulted in more precise estimates. As such, the relationship between the core job components, mental health, and PA can be affected by personal variables, particularly sex, job tenure, and income. It is concluded that PA may not support mental health in African academics in a post-COVID-19 situation that requires the performance of job tasks while observing social distancing protocols.

Availability of Data and Material Data will be made available upon request.

Code Availability Not applicable.

Author Contribution NA conceived the research idea, analyzed the data, and wrote the original manuscript. FFO designed the online survey and coordinated data gathering. FM coordinated data gathering in Kenya whereas ED contributed to the refinement of the research idea. SMA and IA facilitated the distribution of the online survey. AO coordinated the distribution of the online survey in Nigeria. HKM contributed to the study design and conceptualization. SH, RSB, EE and CAM coordinated questionnaire distribution. All authors proofread the draft manuscript and suggested corrections.

\section{Declarations}

Conflict of Interest The authors declared no conflicts of interest.

Ethics Approval This study received ethical clearance from an institutional ethics committee ((\# 0022020ACE). The ethics committee reviewed the study protocol and the informed consent statement. All participants consented to participate in this study. 
Consent to Participate All authors consented to participate.

Consent for Publication Not applicable.

\section{References}

Ahlburg, D. A. (2020). Covid-19 and UK universities. The Political Quarterly, 91(3), 649-654. https://doi.org/10.1111/1467-923x. 12867.

Andreassen, C. S., Pallesen, S., \& Torsheim, T. (2018). Workaholism as a mediator between work-related stressors and health outcomes. International Journal of Environmental Research and Public Health, 15(1), 73. https://doi.org/10.3390/ijerph15010073.

Aperribai, L., Cortabarria, L., Aguirre, T., Verche, E., \& Borges, A. (2020). Teacher's physical activity and mental health during lockdown due to the COVID-2019 pandemic. Frontiers in Psychology, 11, 1-14. https://doi.org/10.3389/fpsyg.2020.577886.

Armitage, R., \& Nellums, L. B. (2020). COVID-19 and the consequences of isolating the elderly. The Lancet Public Health, 5, e256. https:// doi.org/10.1016/s2468-2667(20)30061-x.

Asiamah, N., Mends-Brew, E., \& Boison, B. K. T. (2019). A spotlight on cross-sectional research: Addressing the issues of confounding and adjustment. International Journal of Healthcare Management, 12(4), 1-14. https://doi.org/10.1080/20479700.2019.1621022.

Asiamah, N. \& Danquah (2019). A comparative analysis of the influences of specialized and non-specialized emotional intelligence training on patient satisfaction. International Journal of Healthcare Management. 4(12), 1-12. https://doi.org/10.1080/20479700.2019. 1641652.

Asiamah, N., Kyriakos, K. \& Opoku, E. (2020). The influence of physicians' physical activity prescription on indicators of health service quality. Journal for Healthcare Quality, 1-7. https://doi.org/10. 1097/JHQ.0000000000000275.

Asiamah, N., Opuni, N. F., Mends-Brew, E., Mensah, S. W., Mensah, H. K., \& Quansah, F. (2020). Short-term changes in behaviors resulting from COVID-19-related social isolation and their influences on mental health in Ghana. Community Mental Health Journal, 57, 79-92. https://doi.org/10.1007/s10597-020-00722-4.

Barello, S., Caruso, R., Palamenghi, L., Nania, T., Dellafiore, F., Bonetti, L., Silenzi, A., Marotta, C. \& Graffigna, G. (2021). Factors associated with emotional exhaustion in healthcare professionals involved in the COVID-19 pandemic: An application of the job demandsresources model. International Archives of Occupational and Environmental Health, 1-11. Doi: https://doi.org/10.1007/s00420021-01669-z.

Benedetti, T. R. B., Borges, L. J., Petroski, E. L., \& Gonçalves, L. H. T. (2008). Physical activity and mental health status among elderly people. Rev Saúde Pública, 42(2), 1-6. https://doi.org/10.1590/ S0034-89102008005000007.

Blackmore, J. (2020). The carelessness of entrepreneurial universities in a world risk society: A feminist reflection on the impact of Covid-19 in Australia. Higher Education Research \& Development, 39(7), 1332-1336. https://doi.org/10.1080/07294360.2020.1825348.

Booket, E. J., Dehghan, F., \& Alizadeh, Z. (2018). The role of predicting the formation of workaholism based on personality factors and perfectionism in academics. Cogent Psychology, 5(1), 1-11. https://doi. org/10.1080/23311908.2018.1527200.

Chau, J. Y., Van Der Ploeg, H. P., Dunn, S., Kurko, J., \& Bauman, A. E. (2012). Validity of the occupational sitting and physical activity questionnaire. Medicine and Science in Sports and Exercise, 44(1), 118-125. https://doi.org/10.1249/MSS.0b013e3182251060.

Christie, C.D., Consoli, A., Ronksley, P.E., Vena, J.E., Friedenreich, C.M. \& McCormack, G.R. (2020). Associations between the built environment and physical activity among adults with low socioeconomic status in Canada: A systematic review. Canadian Journal of Public Health, 1-14. Doi: https://doi.org/10.17269/ s41997-020-00364-9.

Christman, Z. J., Wilson-Genderson, M., Heid, A., \& Pruchno, R. (2019). The effects of neighborhood built environment on walking for leisure and for purpose among older people. The Gerontologist, 59(1), 1-10. https://doi.org/10.1093/geront/gnz093.

Chudyk, A. M., McKay, H. A., Winters, M., Sims-Gould, J., \& Ashe, M. C. (2017). Neighborhood walkability, physical activity, and walking for transportation: A cross-sectional study of older adults living on low income. BMC Geriatrics, 17(1), 1-14. https://doi.org/10.1186/ s12877-017-0469-5.

Clark, C., Davila, A., Regis, M., \& Kraus, S. (2020). Predictors of COVID-19 voluntary compliance behaviors: An international investigation. Global Transitions, 2, 76-82. https://doi.org/10.1016/j.glt. 2020.06.003.

D'Avanzo, B., Shaw, R., Riva, S., Apostolo, J., Bobrowicz-Campos, E., Kurpas, D., Bujnowska, M., \& Holland, C. (2017). Stakeholders' views and experiences of care and interventions for addressing frailty and pre-frailty: A meta-synthesis of qualitative evidence. PLoS One, 12(7), 1-22. https://doi.org/10.1371/journal.pone.0180127.

Demerouti, E., Bakker, A. B., Nachreiner, F., \& Schaufeli, W. B. (2001). The job demands-resources model of burnout. Journal of Applied Psychology, 86, 499-512. https://doi.org/10.1037/0021-9010.86.3. 499.

Dhawan, S. (2020). Online learning: A panacea in the time of COVID-19 crisis. Journal of Educational Technology System, 49(1), 5-22. https://doi.org/10.1177/0047239520934018.

Ding, D., Mutrie, N., Bauman, A., Pratt, M., Hallal, P. R. C., \& Powell, K. E. (2020). Physical activity guidelines 2020: Comprehensive and inclusive recommendations to activate populations. The Lancet, 396, 1-3. https://doi.org/10.1016/s0140-6736(20)32229-7.

Dogra, S., \& Stathokostas, L. (2012). Sedentary behavior and physical activity are independent predictors of successful aging in middleaged and older adults. Journal of Aging Research, 2012, 1-8. https:// doi.org/10.1155/2012/190654.

Duncan, G. E., Avery, A. R., Seto, E., \& Tsang, S. (2020). Perceived change in physical activity levels and mental health during COVID19: Findings among adult twin pairs. PLoS One, 15(8), 1-11. https:// doi.org/10.1371/journal.pone.0237695.

Dunton, G. F., Do, B., \& Wang, S. D. (2020). Early effects of the COVID-19 pandemic on physical activity and sedentary behavior in children living in the U.S. BMC Public Health, 20, 1-13. https:// doi.org/10.1186/s12889-020-09429-3.

Egan, C. A., Webster, C. A., Beets, M. W., Weaver, R. G., Russ, L., Michael, D., Nesbitt, D., \& Orendorff, K. L. (2019). Sedentary time and behavior during school: A systematic review and meta-analysis. American Journal of Health Education, 50(5), 283-290. https://doi. org/10.1080/19325037.2019.1642814.

Elsahory, N., Al-Sayyed, H., Odeh, M., McGrattan, A., \& Hammad, F. (2020). Effect of Covid-19 on food security: A cross-sectional survey. Clinical Nutrition ASPEN, XXX(XXX), 1-9. https://doi.org/10. 1016/j.clnesp.2020.09.026.

Fasihi Harandi, T., Mohammad Taghinasab, M., \& Dehghan Nayeri, T. (2017). The correlation of social support with mental health: A meta-analysis. Electronic Physician, 9(9), 5212-5222. https://doi.org/ $10.19082 / 5212$.

Garson, D. (2012). Testing statistical assumptions. Statistical Associates Publishing - Blue Book Publishing, 2012 edition, pp. 1-52.

George, E. S., Kolt, G. S., Rosenkranz, R. R., \& Guagliano, J. M. (2014). Physical activity and sedentary time: Male perceptions in a university work environment. American Journal of Men's Health, 8(2), 148-158. https://doi.org/10.1177/1557988313497217.

Greer, M. K. A. E. (2015). Sedentary behavior and related factors among full-time, university faculty. International Journal of Workplace 
Health Management, 8(3), 206-213. https://doi.org/10.1108/ IJWHM-09-2014-0034.

Guthold, R., Stevens, G. A., Riley, L. M., \& Bull, F. C. (2018). Worldwide trends in insufficient physical activity from 2001 to 2016: A pooled analysis of 358 population-based surveys with 1.9 million participants. The Lancet Global Health, 6, 1077-1086. https://doi.org/10.1016/S2214-109X(18)30357-7.

Hamer, M., Stamatakis, E., \& Steptoe, A. (2009). Dose-response relationship between physical activity and mental health: The Scottish health survey. British Journal of Sports Medicine, 43, 1111-1114. https://doi.org/10.1136/bjsm.2008.046243.

Harrington, D. M., \& O'Reilly, M. (2020). The reimagination of schoolbased physical activity research in the COVID-19 era. PLOS Medicine, 17(8), 1-3. https://doi.org/10.1371/journal.pmed. 1003267

Hochbaum, G., Rosenstock, I., Kegels, S. (1952). Health belief model. U.S. Public Health Service.

Hogan, V., Hogan, M., \& Hodgins, M. (2016). A study of workaholism in Irish academics. Occupational Medicine, 66(6), 460-465. https:// doi.org/10.1093/occmed/kqw032.

Jacob, O. N. (2020). Impact of COVID-19 pandemic school close down on the research programme of higher institutions. International Journal of Advances in Data and Information Systems, 1(1), 40 49. https://doi.org/10.25008/ijadis.v1i1.189.

Jordan, P. J., \& Troth, A. C. (2020). Common method bias in applied settings: The dilemma of researching in organizations. Australian Journal of Management, 45(1), 1-12. https://doi.org/10.1177/ 0312896219871976.

Lavelle, G., Noorkoiv, M., Theis, N., Korff, T., Kilbride, C., Baltzopoulos, V., Shortland, A., Levin, W., \& Ryan, J. M. (2020). Validity of the international physical activity questionnaire short form (IPAQ-SF) as a measure of physical activity (PA) in young people with cerebral palsy: A cross-sectional study. Physiotherapy, 107, 209-215. https://doi.org/10.1016/j.physio.2019.08.013.

Lindner, T., Puck, J., \& Verbeke, A. (2019). Misconceptions about multicollinearity in international business research: Identification, consequences, and remedies. Journal of International Business Studies, 51, 283-298. https://doi.org/10.1057/s41267-019-00257-1.

Lindsay, D. B., Devine, S., Sealey, S. M., \& Leicht, A. S. (2016). Time kinetics of physical activity, sitting, and quality of life measures within a regional workplace: A cross-sectional analysis. $B M C$ Public Health, 16, 1-9. https://doi.org/10.1186/s12889-016-3487-x.

Lukat, J., Margraf, J., Lutz, R., van der Veld, W. M., \& Becker, E. S. (2016). Psychometric properties of the positive mental health scale (PMH-scale). BMC Psychology, 4(1), 1-14. https://doi.org/10.1186/ s40359-016-0111-x.

Mackenzie, K., Goyder, E., \& Eves, F. (2015). Acceptability and feasibility of a low-cost, theory-based and co-produced intervention to reduce workplace sitting time in desk-based university employees. BMC Public Health, 15, 1-13. https://doi.org/10.1186/s12889-0152635-Z.

Meyer, J., McDowell, C., Lansing, J., Brower, C., Smith, L., Tully, M., \& Herring, M. (2020). Changes in physical activity and sedentary behavior in response to COVID-19 and their associations with mental health in 3052 US adults. International Journal of Environmental Research and Public Health, 17(18), 1-13. https://doi.org/10.3390/ ijerph17186469.

Meyer, M., Zill, A., Dilba, D., Gerlach, R. \& Schumann, S. (2021). Employee psychological well-being during the COVID-19 pandemic in Germany: A longitudinal study of demands, resources, and exhaustion. International Journal of Psychology, 1-19. https://doi. org/10.1002/ijop.12743.

Min, J., Ailshire, J., \& Crimmins, E. M. (2016). Social engagement and depressive symptoms: Do baseline depression status and type of social activities make a difference? Age and Ageing, 45(6), 838843. https://doi.org/10.1093/ageing/afw125.
Muhumuza, R. \& Odula, T. (2020). As schools reopen in Africa, relief is matched by anxiety. Retrieved on 01/12/2020 at 11:34 AM from https://abcnews.go.com/International/wireStory/schools-reopenafrica-relief-matched-anxiety-74228908

Nyenhuis, S. M., Greiwe, J., Zeiger, J. S., Nanda, A. \& Cooke, A. (2020). Exercise and fitness in the age of social distancing during the COVID-19 pandemic. The Journal of Allergy and Clinical Immunology: In Practice. Editorial, 1-4. https://doi.org/10.1016/j. jaip.2020.04.039.

Oyeyemi, A. L., Bello, U. M., Philemon, S. T., Aliyu, H. N., Majidadi, R. W., \& Oyeyemi, A. Y. (2014). Examining the reliability and validity of a modified version of the international physical activity questionnaire, long form (IPAQ-LF) in Nigeria: A cross-sectional study. BMJ Open, 4(12), 1-11. https://doi.org/10.1136/bmjopen-2014005820.

Peluso, M. A. M., \& de Andrade, L. H. S. G. (2005). Physical activity and mental health: The association between exercise and mood. Clinics, 60(1), 61-70. https://doi.org/10.1590/S1807-59322005000100012.

Picavet, H. S. J., Pas, L. W., van Oostrom, S. H., van der Ploeg, H. P., Verschuren, W. M. M., \& Proper, K. I. (2016). The relation between occupational sitting and mental, cardiometabolic, and musculoskeletal health over a period of 15 years - the Doetinchem cohort study. PLoS One, 11(1), 1-11. https://doi.org/10.1371/journal.pone. 0146639 .

Podsakoff, P. M., MacKenzie, S. B., Lee, J.-Y., \& Podsakoff, N. P. (2003). Common method biases in behavioral research: A critical review of the literature and recommended remedies. Journal of Applied Psychology, 88(5), 879-903. https://doi.org/10.1037/ 0021-9010.88.5.879.

Proper, K. I., Cerin, E., Brown, W. J., \& Owen, N. (2007). Sitting time and socio-economic differences in overweight and obesity. International Journal of Obesity, 31, 169-176. https://doi.org/10. 1038/sj.ijo.0803357.

Proper, K. I., Picavet, H. S. J., Bemelmans, W. J. E., Verschuren, W. M. M., \& Wendel-Vos, G. C. W. (2012). Sitting behaviors and mental health among workers and nonworkers: The role of weight status. Journal of Obesity, 2012, 1-9. https://doi.org/10.1155/2012/ 607908.

Richiardi, L., Bellocco, R., \& Zugna, D. (2013). Mediation analysis in epidemiology: Methods, interpretation and bias. International Journal of Epidemiology, 42(5), 1511-1519. https://doi.org/10. 1093/ije/dyt127.

Sahlqvist, S., Song, Y., Bull, F., Adams, E., Preston, J., \& Ogilvie, D. (2011). Effect of questionnaire length, personalisation and reminder type on response rate to a complex postal survey: Randomised controlled trial. BMC Medical Research Methodology, 11, 1-8. https:// doi.org/10.1186/1471-2288-11-62.

Shahnazi, H., Ahmadi-Livani, M., Pahlavanzadeh, B., Rajabi, A., Hamrah, M. S., \& Charkazi, A. (2020). Assessing preventive health behaviors from COVID-19: A cross sectional study with health belief model in Golestan Province, Northern of Iran. Infectious Diseases of Poverty, 9(1), 1-9. https://doi.org/10.1186/s40249020-00776-2.

Simons, C. C. J. M., Hughes, L. A. E., van Engeland, M., Goldbohm, R. A., van den Brandt, P. A., \& Weijenberg, M. P. (2013). Physical activity, occupational sitting time, and colorectal cancer risk in the Netherlands cohort study. American Journal of Epidemiology, 177(6), 514-530. https://doi.org/10.1093/aje/kws280.

Sun, J., Sun, R., Jiang, Y., Chen, X., Li, Z., Ma, Z., Wei, J., He, C., \& Zhang, L. (2020). The relationship between psychological health and social support: Evidence from physicians in China. PLoS One, 15(1), 1-19. https://doi.org/10.1371/journal.pone.0228152.

Thivel, D., Tremblay, A., Genin, P. M., Panahi, S., Rivière, D., \& Duclos, M. (2018). Physical activity, inactivity, and sedentary behaviors: Definitions and implications in occupational health. Frontiers in Public Health, 6, 1-5. https://doi.org/10.3389/fpubh.2018.00288. 
Thornton, J. S., Frémont, P., Khan, K., Poirier, P., Fowles, J., Wells, G. D., \& Frankovich, R. J. (2016). Physical activity prescription: A critical opportunity to address a modifiable risk factor for the prevention and management of chronic disease: A position statement by the Canadian academy of sport and exercise medicine. British Journal of Sports Medicine, 2016, 1-6. https://doi.org/10.1136/ bjsports-2016-096291.

Torp, S., Lysfjord, L., \& Midje, H. (2017). Does the work environment force university academics into workaholism and work-family conflict? European Journal of Public Health, 27(3), 36. https://doi.org/ 10.1093/eurpub/ckx187.090.

Torp, S., Lysfjord, L., \& Midje, H. H. (2018). Workaholism and workfamily conflict among university academics. Higher Education, 120. https://doi.org/10.1007/s10734-018-0247-0.

Upoalkpajor, J. N., \& Upoalkpajor, C. B. (2020). The impact of COVID19 on education in Ghana. Asian Journal of Education and Social Studies, 9(1), 23-33. https://doi.org/10.9734/ajess/2020/v9i130238.

Varea, V. \& González-Calvo, G. (2020). Touchless classes and absent bodies: Teaching physical education in times of Covid-19. Sport, Education and Society. 1-15. https://doi.org/10.1080/13573322. 2020.1791814 .
Venkatesh, A., \& Edirappuli, S. (2020). Social distancing in covid-19: What are the mental health implications? British Medical Journal, 369, 1. https://doi.org/10.1136/bmj.m1379.

Veroma, V., Kautiainen, H., \& Korhonen, P. E. (2017). Physical and mental health factors associated with work engagement among Finnish female municipal employees: A cross-sectional study. BMJ Open, 7(10), 1-5. https://doi.org/10.1136/bmjopen-2017017303.

Wanner, M., Probst-Hensch, N., Kriemler, S., Meier, F., Autenrieth, C., \& Martin, B. W. (2016). Validation of the long international physical activity questionnaire: Influence of age and language region. Preventive Medicine Reports, 3, 250-256. https://doi.org/10.1016/ j.pmedr.2016.03.003.

Yankholmes, A. K. (2014). Publish or perish: African scholarship in the field of tourism and hospitality studies. Tourism and Hospitality Research, 14(1-2), 97-107. https://doi.org/10.1177/ 1467358414536180 .

Publisher's Note Springer Nature remains neutral with regard to jurisdictional claims in published maps and institutional affiliations.

\section{Affiliations}

\section{Nestor Asiamah ${ }^{1,2}$ (D) Faith Muhonja ${ }^{3}$ - Akinlolu Omisore ${ }^{4}$. Frank Frimpong Opuni ${ }^{5}$ Henry Kofi Mensah ${ }^{6}$. Emelia Danquah $^{7} \cdot$ Simon Mawulorm Agyemang ${ }^{8} \cdot$ Irene Agyemang $^{9} \cdot$ Sylvester Hatsu $^{10} \cdot$ Rita Sarkodie Baffoe $^{11}$. Eric Eku ${ }^{12} \cdot$ Christiana Afriyie Manu ${ }^{11}$}

1 School of Health and Care Professions, University of Portsmouth, Winston Churchill Ave, Portsmouth PO1 2UP, UK

2 Africa Centre for Epidemiology, P. O. Box AN, 16284 Accra, Ghana

3 School of Public Health, Mount Kenya University, Thika, Kenya

4 Department of Community Medicine, Osun State University, Osogbo, Nigeria

5 Department of Marketing, Accra Technical University, Accra, Ghana

6 Human Resources and Organizational Development, Kwame Nkrumah University of Science and Technology, Kumasi, Ghana
7 Logistics and Supply Chain Management, Koforidua Technical University, Koforidua, Ghana

8 Department of Physical Education and Health, Abetifi Presbyterian College of Education, Abetifi, Ghana

9 West African Postgraduate College of Pharmacists, Accra, Ghana

10 Department of Computer Science, Accra Technical University, Accra, Ghana

11 School of Business, Accra Technical University, Accra, Ghana

12 Institute for Distance Education and E-learning, University of Education, Winneba, Ghana 